\title{
Del deber a la ilusión. (Notas para una ética de Ortega)
}

\author{
JOSE LASAGA MEDINA \\ I.B. Lope de Vega, Madrid
}

\section{Una ética para la circunstancia}

La reflexión sobre la moral en Ortega se desarrolla en una serie de ecomplicacionesn, cuyo punto de partida está en la teoría del héroe de Meditaciones del Quijote, ' en la relación entre "tragedias e eilusión". El motivo de la tragedia es traido por la libertad del héroe; es heroe quien se resuelve a ser "él mismo", a fundar sobre sí sus actos contra lo «dado»: los usos caducos, los ideales históricamente periclitados o en crisis. Y el de la ilusión, por el reconocimiento de que la vida humana necesita precisamente de ideales para ser vida wen formas, plena, pues lo real - wel peso grave de la existencia»amenaza de fracaso los proyectos del héroe. En el ejercicio de su libertad el heroe puede convertirse en un personaje desesperado o ridículo. $Y$ perder la ilusión. Pero, por su parte, el doble sentido que tiene la palabra «ilusión" en español, ya avisa de su peligro: que degenere en alucinación, que suplante el heroe con su ideal la realidad. Así, se hace necesaria la intervención de la ironía: para que comunique la svoluntad de aventuran ( $\mathrm{y}$ sus ilusiones) con la dtreza y resistencia de lo real, para que componga lo trágico de una libertad que no alcanza a ver el fin de su jornada con la ilusión que surge de creer que aguarda un poco más adelante la posada y el hogar: seguridad y reposo por una noche. La mediación de la ironía impide que se despliegue cualquiera de los peligros -desespera- ción o alucinación- que amenazan la ruptura del estable desequilibrio entre tragedia e ilusión. Aquí la ironía es cultura, ${ }^{2}$ creacion de ideales, actividad de una razón que aún cree -aunque con reservas- que es la única instancia capaz de "salvar» la circunstancia.

Reservas que en Ortega no harán sino crecer, pues si la ocupación del heroe es proyectar ideales (concebirlos y realizarlos), éstos no pueden ser gestados por la razón "racionalista" que había ironizado (en el sentido ahora de "disminuir", "rebajar") la vida, fascinada ante su propio poder. Lo que conduce a la segunda complicación de su ética: la cultura, la razón, no son suficientes. El ideal culturalista de la ciencia, la norma ética y la cosa bella olvida aquello por lo que los hombres se esfuerzan en producir tales objetos: sus vidas.

Aparece así el motivo de la espontaneidad y con ella, una segunda ironía (ya aludida en la nota 2). La vida espontánea frente a la vida normativizada de la cultura: se trata de reconducir la imagen de la libertad, interpretada sobre el motivo del esfuerzo heroico-violencia que el querer impone al ser, presión destructora del ideal sobre lo real hacia la libertad como espontaneidad. Ésta es más radical porque es anterior: el deseo y la fantasía son las fuentes capaces de alimentar, por decirlo así, desde abajo, a la razón. De ahí que el querer racional esté articulado sobre ese otro preferir propio de la espontaneidad. 
El propósito de Ortega no es tanto el de poner la espontaneidad en lugar de la razón, como el de volverlas mutuamente porosas: obligar a la razón a reconocer que es afectada por motivos arracionales, y que no debe despreciarlos, pues no puede esperar tener éxito en sus fines y creaciones ideales si desatiende las exigencias de su propia espontaneidad vital.

La lucha de Ortega contra el siglo $\mathrm{xIX}$ y su herencia (idealismo, romanticismo, pragmatismo político-economico) le lleva a contraponer a la ironía de Socrates-Kant ${ }^{3}$ la ironía cervantina puesta al dra: la ironfa de Don Juan -un Don Juan rinteligente" que ha comprendido la critica cervantina del esfuerzo puro, ${ }^{4}$ que conoce a Aristóteles y acepta vivir su tiempo sin nostalgia, inventando idcales porque no los hay.

La actitud de S6crates consistio en sustituir lo espontáneo por lo racional (III, 176) para alcanzar un ideal ético cifrado en la encracia y la suficiencia ${ }^{5}$ versión antigua de la autonomia-autarquía kantiana. Este ideal ético se basa en la suspension de los deseos upara seguir docilmente los mandatos racionales» (ibid.). En la contraposición espontaneidad/racionalidad, Ortega apuesta, como es sabido, por la restitución de derechos a la espontaneidad, lo que da una apariencia vitalista a las publicaciones de los años veinte (y especialmente a El tema de nuestro tiempo). No sé si se toma suficientemente en cuenta que estc "vitalismon orteguiano es el producto de una ironía "realistan, esto es, con vocación de reconocer lo que hay y lo que somos. Quiero decir que no reivindica la vitalidad como un ideal, ni siquiera como una solucion, sino como la condición de posibilidad de una ética que reconozca el modo de ser de la vida humana. En este sentido, el ideal a elaborar ha de pasar por el factum de espontaneidad que nos constituye pues su olvido condena a la razón a la falsificación o al fracaso. No se pierda de vista que la ironía es un decir oblicuo que oculta aquello de lo que realmente se ocupa. Socrates tiene un problema con la vida (en esta sospecha se basa la, menos arbitraria de lo que parece, interpretación de Nietzsche); ${ }^{6}$ su problema es la vida; su solución, la razón. El Ortega educado en el neokantismo tiene un problema con la razón; tras su defensa de la espontaneidad se esconde un esfuerzo por pensar un nuevo modelo racional. ${ }^{7}$ Si la ironía socratica es tomarse en serio lo racional, «el hombre del presente [simbolizado por Don Juan] desconfía de la razón y la juzga a través de la espontaneidad" (III, 178). Obsćrvese que ajuzgar" es una actividad racional, por lo que difícilmente pretenderá Ortega deshacerse de la razón, sino ajustar la razón a la vida, es decir, buscar un modelo de «razón vital». Igualmente, desde el punto de vista moral, tampoco está Ortega -y se ha dicho algunas veces - prescindiendo de toda normatividad ética. Lo que expone es el hecho de que el ideal wencráticon de Sócrates es un ideal que presupone muchedumbre de deseos, salud de estimaciones, abundancia de energías, ideales vivos $\mathrm{y}$ creadores, esto es, ilusion; por tanto, una personalidad capaz de vivir desde sí misma y un mundo abierto, complejo, con relieves y desniveles. Los hombres desvitalizados y resentidos ${ }^{8}$ no pueden sino invertir el signo del ideal autárquico usándolo contra el otro, sirviéndose de el para uniformarlo y aplastar toda diferencia. Socrates pulveriza al héroe griego (III, 541). Don Juan ironiza la encracia socrática con la esperanza de que en el algebra del menos por menos más, se libere la forma heroica y cuasitrágica de una voluntad libre que está 
dispuesta a decir sí a la vida: "La gracia insuperable de lo real [...]; la plenaria aceptación de la vida y de sus condiciones [...]: la moral más elevada y el arte mejor dependen de esa anuencia valerosa, del trágico si dado a la vidam (II, 233). Un sí a la vida mediado por la ironía que atiende a lo que hay, a lo real, para descubrir en sus texturas lo valioso, lo idealizable. El caso es que si no hay ideales, habrá que inventarlos. ¿Cómo? Convirtiéndose en el organo adecuado de visión. El héroe debe ser menos esforzado que magnánimo, entendiendo la magnanimidad no sólo como una virtud del querer, sino como disposición del corazón a conceder a lo real su multilateralidad, sus "salvaciones», en el sentido en que emplea Ortega esta expresion al principio de Meditaciones del Quijote: lo que lleva a las cosas a su posible perfección. $\mathrm{Si}$, como disposición, se entiende la magnanimidad en términos psicológicos - talante o carácter anímicos- no se llega al fondo de lo que significa este concepto en la moral orteguiana ni de la función clave que desempeña. Es cierto que el propio Ortega habla de la magnanimidad en términos psicológicos (p. e. «las almas tienen diferentes formatos" [III, 609]); pero vista desde la vida humana individual como quehacer dramático, la magnanimidad es el principio stico que se realiza en el cumplimiento de la propia misión, esto es, predisposición para el cumplimiento de la vocación en la circunstancia no elegida, aceptación del destino. Es más, no es preciso salir de la página antes citada para que vincule Ortega la idea de magnanimidad con las de "misión creadora" y "forzosidad del propio destinow. Ramos Mattei interpreta la magnanimidad como la traducción "a términos concretos" del "principio formal de la autenticidad": "La magnanimidad" significa la acep- tación auténtica y generosa de lograr el propio destino, de "henchir" el propio destino, como limitación histórica y posibilidad propia concretas.9

Don Juan es héroe porque es la muerte el fondo esencial de su vida (VI, 136). Pero es también jovial y animoso porque «está dispuesto a derramar su vida precisamente por algo que sea capaz de llenarlas (VT, 137). $\mathrm{Y}$ eso que es capaz de llenar la vida es a lo que llamamos ideal y hay hombres que buscan disparar sus vidas hacia el blanco de un ideal: «Este símil del ideal como un blanco y nuestra existencia como una flecha no es mío [...]. En el comienzo de su Etica, dice Aristóteles: "Busca el arquero con la mirada un blanco para sus flechas, ¿y no lo buscaremos para nuestras vidas?". Bajo tal metáfora pierde la ética su cariz pedantesco que en nuestro tiempo ha tomado, y parece convertirse en una noble disciplina deportiva, que puede resumir sus imperativos asi: ¡Hombres, sed buenos arqueros!n (ibid.). ${ }^{10}$

El imperativo no es baladí; pues significa que acertar en la vida - y eso es lo que entiende Ortega en última instancia por ética- exige buscar el objeto a que ponerla. La metáfora del arquero remite al imperativo de Pindaro:" "Llega a ser el que eres" es, en la simplicidad de su formulacion, un imperativo sumamente complejo. Manda, por lo pronto, mirar hacia dentro para rescatar de una subjetividad dominada por las representaciones formalistas y utilitaristas el auténtico sentimiento, el deseo de ser el que se tiene que ser, el deseo del propio destino (que en Ortega es siempre individual e intransferible). Así, es el imperativo que ordena asumir éticamente la propia vída, "convertirse" ${ }^{2}$ en actor consciente y responsable, verdadero "sujeto ético" en una época en que éste habia co- 
menzado a disolverse en lo social -en cualquiera de sus formas: lo socialnacional o lo social-revolucionario-, lo psicológico-inconsciente, etc.; y es también imperativo de creación de los "blancos" a los que poner la vida pues éstos no son "dados" en la transparencia de una voluntad pura que quiere, por todo querer, la ley de una razón universalizante y abstracta. $Y$, a la vez, simultáneamente, imperativo de destrucción, critica o ironia: rechazo de aquello que ciega las fuentes de la ilusión. El "héroe" orteguiano lo es porque no desespera en un mundo en que lo razonable es desesperar... o resentirse; porque no se instala en la tragedia, sino que le busca la espalda y reinventa la aventura; porque sin ideales a la vista, se da la tarea de crearlos. Es héroe hacia dentro y hacia fuera, héroe de circunstancias. Acaso no le guste serlo, pero no queda más remedio. Héroe en la inseguridad permanente del que asiste como testigo irónico a su propia existencia. En definitiva, este héroe lo es porque vive en un mundo en que la heroicidad es la única forma de salvación y afirmación ética: porque nace adscrito a una época, a una tradición, a unos ideales (o a la ausencia de éstos) que no elige, pero en unas condiciones en que es inaplazable elegir y hasta crear las condiciones de la elección. Nada de esto puede constituir objeto de deber. De ahr que en 1929 escriba Ortega: «La ética que acaso el año que viene exponga [...] se diferencia de todas las tradicionales en que no considera al deber como la idea primaria en la moral, sino a la ilusión. El deber es cosa importante pero secundaria -es el sustituto, el Ersatz de la ilusion. Es preciso que hagamos siquiera por deber lo que no logramos hacer por ilusión" (VII, 426).

Pero si a Ortega le repugna el insincero culturalismo, no le parece menos digno de repudio el «adanismo» y el capricho. Al proponerse devolver al sujeto ético su propia subjetividad, no ignora que el peligro que acecha es el del subjetivismo. La integracion de lo sensible y lo racional, despues de la separación kantiana, es el motivo que atraviesa toda la ética y la metafísica orteguianas, condensado en el problema de la vida humana como autenticidad.

No son sino variaciones de la misma tesis la exigencia de usalvación de la circunstancian de Meditaciones, el pindárico «llega a ser el que eresn de «Estética en el tranvía» o el de alealtad con nosotros mismos" que se propone en El tema de nuestro tiempo como complemento y correctivo del imperativo de objetividad de la tradición neokantiana. $\mathrm{Y}$ todas presuponen los elementos esenciales de la metafísica orteguiana: que la realidad en última instancia es una perspectiva que ata indisolublemente a un yo a una circunstancia. Y no cae Ortega en el subjetivismo porque el yo no es transparente a sf mismo; concebido como proyecto y vocación, el yo sólo puede reconocer su propia textura en su quehacer. Son sus acciones quienes le revelan su identidad que ni está dada ni es firme. No es que "deba" comprometerse con la circunstancia, es que lo está, quiera o no, de raíz. Así, los deseos espontáneos han de contrastarse con la nada subjetiva resistencia del mundo, con sus aristas y leyes. Por tanto, la lealtad para con uno mismo es inseparable de la fidelidad a la circunstancia, del respeto a lo que hay, pues las claves del acierto para una vida buena residen tanto en descubrir los envios de una subjetividad que solo habla a media voz y los de una circunstancia que impone al yo unas exigencias de realidad historicamente dadas. Esto significa que la ética de Ortega es circunstan- 
cial, que sus imperativos surgen de la precisa figura que los tiempos recortan sobre el telón de fondo de la existencia: "En arte, como en moral, no depende el deber de nuestro arbitrio; hay que aceptar el imperativo de trabajo que la época nos impone. Esta docilidad a la orden del tiempo es la única probabilidad de acertar que el individuo tienew (III, 360).

$Y$ porque la época dibuja un paisaje sin ideales propone Ortega una ética creadora de las condiciones para que pueda haber vida «buena». De ahf que su ética lo sea de creación de ilusiones, del esfuerzo lujoso y deportivo, ética de perfección porque es preciso invitar al viviente a esforzarse "deportivamente" en la tarea de crear sus ideales, porque no halla en su vida horizonte de aquellos. $\mathrm{Y}$ al mismo tiempo es una ética arealista" en un doble sentido: en el inmediato, que supone no alejar a los ideales de la realidad, prioridad del ser sobre el deber-ser; $y$ en el irónico que whace de menos» a esa misma realidad para hacer hueco a la ilusión y a la creación de "imposibles". Es este aspecto de la ética orteguiana el que describe Cerezo bajo el término «ideal de salud», opción igualmente equidistante del respiritu de la utopia” y del xespiritu de la resignación». Este ideal de salud consiste, en lo esencial, en una nueva forma de entender las relaciones entre el mundo de lo real dado y el de sus posibles, esto es, el de los ideales que pueden acrecentarlo, en definitiva, salvarlo. "Ortega propone como regimen de salud" - frente al idealismo ético que se empefia en whacer el poder de lo que quiere, sin reparar en la posibilidad interna de este»-., «querer el poder, o lo que es lo mismo, querer la posibilidad [...]. Pero querer la posibilidad no implica un abandono de los ideales, sino su recusación como valores absolutos, y a la vez, el rodeo necesario para que, en su lugar y hora, lleguen a ser efectivosm. ${ }^{13}$

\section{Ilusion y creación de ideales: el "esfuerzo deportivo"}

En contra de la que se ha dicho, Ortega no habla de moral lujosa y esfuerzo deportivo por sus convicciones vitalistas y biologistas, sino que sidealiza" la vida porque es la única tierra - realidad radical- en la que, quiera o no, tiene el hombre que vivir y plantearse, por tanto, si es posible una existencia aproximadamente felicitaria.

La idea de la vida como deporte es más seria de lo que parece.

Las criticas a la ética deportiva que normalmente se basan en una interpretación "vitalista" -término que apenas oculta el marchamo implicito de sirracionalismon- del pensamiento orteguiano de los años veinte me parecen futera de lugar: se interpreta el esfuerzo deportivo como un eprincipio de creaciones superfluas»: asi Morón Arroyo. ${ }^{14}$ Esto es, simplemente, ignorar que Ortega piensa bajo la idea del deporte el problema de la libertad: el deporte como una actividad humana que se da a sí misma -libremente- su propio fin. La adhesión de Ortega a la moral "deportiva" se revela, pues, no como sumisión a una moda de la época, sino como uno de los componentes fundamentales de la dimensión ética de la vida humana individual. Morón Arroyo sigue aquí la interpretación que podríamos llamar "canónica" de la ética orteguiana, la del profesor Aranguren, ${ }^{15}$ que resulta ser mucho más matizada y ajustada al texto orteguiano que la de algunos de sus seguidores. La cuestión decisiva no es la de si Ortega tiene una etapa "vitalista", cosa que Aranguren no sostiene al interpretar 
como formas de expresión y no de pensamiento ciertas tesis orteguianas $y$ al hacer suyas las matizaciones de $\mathrm{Fe}$ rrater Mora ${ }^{16}$ a este respecto, sino la de si cel espontáneo y vitalista talante lúdico es cosa bien distinta de una actitud etica por antonomasia"; 17 es decir, si hay una incompatibilidad de raíz entre la ética de la autenticidad y la ética del esfuerzo deportivo tal y como sugiere la pregunta que formula Aranguren: "¿Como ha de entenderse la vida según Ortega: como quehacer moral, responsable, auténtico, o como deporte y juego?".18 La disyunción excluyente que presupone la pregunta implica ya una interpretación de lo que pueda significar en Ortega «deporte» y «juego». Lejos de interesar a éste los aspectos sensibles - lo divertido, lo satisfactorio, lo que tiene de evasión, lo placentero- que tampoco desdeña, los términos se vinculan siempre a lo que juego y deporte significan en la cultura occidental desde Grecia: esfuerzo libre, libre asunción de reglas, pues por tratarse de una actividad que no nos vie. ne impuesta ael juego exige que se juegue lo mejor posible. Precisamente su falta de "seriedad" hacia afuera - su falta de forzosidad- le dota espontáneamente de una rigurosa "seriedad" internas (II, 350).19 El deporte es una actividad lúdica, sólo que ella wincluye un riesgo, aunque sólo sea el de un esfuerzo excesivo. El deportista, en vez de rehuir el peligro, va a él, y por eso es deportista ${ }^{20}$ (II, 431). De modo que al hablar de deporte como ethos se están tocando los temas éticos por antonomasia, los de la individualidad, la libertad, la felicidad y la muerte: «Esta moral mejor -la moral "de la vida alta", la del deportista - habia de advertir al hombre que posee la vida para exponerla con sentidos (II, 432). ${ }^{21}$ «Exponer la vidan: esto ni siquiera es un mandato moral, inspirado en retóricas aventureras; es, simplemente, la constatación de un rasgo estructural de la vida humana concreta e individual, a saber, que la vida se nos da, pero «no se nos da hechan, llena, con sentido; vivir sera -se tenga o no conciencia de ello- «quercr»-un querer más profundo que el de la voluntad entendida como dimensión del espirituque la vida tenga una figura $\mathrm{y}$ un sentido. ¿Y no es esto lo que hemos encontrado en la voluntad del heroe de Meditaciontes, origen de la ética orteguiana? Acaso no sea forzar las cosas ver en la idea de la vida como deporte la tesis de la moral como autenticidad ${ }^{22}$ pues, en definitiva, ésta no manda sino ser fiel al propio destino: llegar a ser el que se tiene que ser; pero sólo cumple el mandato pindárico quien expone su vida a una carta - la de la propia vocación destinadora- que, por lo demás, permanece oculta en el pliegue del propio sfondo insobornables.

( $\mathrm{X}$ porque la vocación permanece oculta y porque la circunstancia es resistente y opaca a nuestras aspiraciones felicitarias, siendo entonces la vida drama, naufragio... tiene que ser reconocida como "puesta" en lo inseguro, esto es, "apuesta» e invención. En definitiva, la ética orteguiana tiene dos referentes que, se podria decir, la determinan. Uno es el de la crisis de la cultura idealista al filo del siglo $\mathrm{xx}$. El otro el de la concepción metafísica que tiene Ortega de lo real: vivir consiste en que cada yo tiene que salvarse salvando su circunstancia. Pero la exigencia de la salvación revela una concepción de lo real como insuficiente, anonadado, en definitiva: como "ser indigente", idea que radicaliza la tradicional de la contingencia, pensada por la filosofía medieval.)

Y no es cierto, en mi opinión, como sugiere Aranguren, que el tema de la autenticidad aparezca después-de-Hei- 
degger, mientras que la ética de talante lúdico y deportivo domine el antesde-Heidegger. Sigue Ortega hablando hasta el final de deporte y juego ${ }^{23}$ y es claro el motivo de la autenticidad en el imperativo pindárico asumido en $1916^{24}$ o en el imperativo de clealtad consigo mismon de El tema de nuestro tiempo (1923). Sin el talante deportivo no se sostiene la ética orteguiana de la ilusión, del entusiasmo, de la magnanimidad y de la autenticidad. En este plexo de motivos, lo deportivo alude al temple heroico, inevitable en una época determinada históricamente o por los ideales aéticos" burgueses (seguridad, utilitarismo, individualismo egoísta, etc.) o por el utopismo postkantiano en cualquiera de sus dos brazos históricos, el romántico (arcaismo, huida del presente, desesperación, spleen -cuya última consecuencia ideológica sera la ética existencialista); o el socialista (con sus éticas de redención colectiva).

Vivir éticamente es, como nos enseña Don Juan, poner la vida a una carta. Pero esto "sin tragedias", pues la asunción de posturas trágicas es incompatible con la ligereza que precisa el uso a fondo de la inteligencia (ensimismamiento) para acertar: "La perfección moral, como toda perfección, es una cualidad deportiva, algo que se añade lujosamente a lo que es necesario $\mathrm{e}$ imprescindible. De aquí que, como en todo deporte, contenga la perfección moral un grano de ironía y se sienta a sí misma sin patetismo al- guno. La mera corrección moral es cosa con que no tiene sentido jugar, porque significa el minimo exigible. Pero la perfección no nos la exige nadie; la ponemos o intentamos nosotros por libérrimo acto de albedrio, y, sin duda, merced a que nos complace su ejercicion (II, 358-359).

El propósito de Ortega no puede ser más claro: elaborar una ética exenta del pathos del deber y de la seriedad. pero no por ello menos moral. La ética orteguiana es circunstancial. Eso quiere decir que se apoya en lo que hay, historicamente hablando; y lo que hay es una sociedad en crisis: crisis de hastío, de falsos ideales, de ausencia de ilusiones. En una sociedad tupida de creencias y convicciones no tendría sentido proponer una moral de la ilusión (en rigor no tendría sentido proponer ninguna moral).

Se revelará, en cambio, como la ética apropiada para un tiempo de crisis -crisis de todo clasicismo, ${ }^{25}$ como dice Ortega en su ensayo "Pidiendo un Goethe desde dentrow - aquella que parta de la constatación de lo que hay -en este caso de lo que no hay: ideales. No se termina de entender la doctrina ética sugerida por Ortega si se mira como el resultado de una crítica profesoral o filologica a teorias anteriores. En mi opinión, hay que verla como su respuesta a la circunstancia histórica que le tocó vivir. En este sentido, la ética orteguiana es un caso ejecutivo de razón histórica.
1. Desarrollada, especialmente en los parágrafos 15, El heroes, y 17, wa tragedia (I, 389-390 y I, 392-394 respectivamente). Todas las citas van referidas a Obras completas, Madrid, Revista de Occidente en Alianza, 1983.

2. La cultura siempre es la negación de la natutaleza, y como on el hombre a lo natural llamamos espontåneo, tendremos que definir la cultura como la negación de lo espontáneo, es decir, la ironfa. $(1,460)$. En este texto, perteneciente al temprano ensayo :Adán en el paralso*, se identifica aúr ironfa con cultura y se contrapone a espontaneidad. Se trata, por tanto, de la ironía que más tarde el propio Ortega criticará como ironía *socrática*, esto es, racionalista* (de razón pura, en el sentido amplio del término), opuesta 
a la ironía de Don Juan o zvitalista. (de razón vital). Sin embargo, en Meditaciones del Quijote la ironfa adquiere un matiz nuevo: la ironfa, en efecto, es cultura, pero en el "modo cervantino de mirar las cosas* - nueva vista sobre lo real no reduccionista y sf multilateral-, modo no coincidente con el neokantiano que sacrifica la diversidad de lo real a la pureza del concepto $y$ al rigor de la norma ética. Si Cervantes define en su Quijote la vida "como naufragio irremisible y esencial derrota* (II, 375), la ironfa de éste no reside en el humor; sino en la comprensión y el afán de salvaciones que derrarna sobre sus criaturas.

3. Socrates-Kant (segín la caracterizacion de El tema de nuestro tiempo) representa la ironfa moderna, cuya crispación conducirá a la ironfa romántica. Cervantes, junto con Leonardo -maestro del equilibrio y de la mesura, tambien en lo etico (véase En lomto a Galileo, V, 89)-, representan, en la perspectiva orteguiana de $M \varepsilon$ ditaciones del Quijote, la ironfa pre-modema, localizada en el breve momento de plenitud que vive Europa antes de comenzar su travesia amodernas.

4. Vease al respecto "Meditación de El Esco. rial. texto casi contemporaneo de Meditaciones. No es amiesgado suponer que Ortega tiene plena conciencia de que al sostener que Cervantes compone en su aQuijote la acritica del esfuerzo puro: esfuerzo simbolizado por la construcción del monasterio, esa critica alcanza por igual al modo de ser del español en la historia y al idealismo extremado de un Fichte, pues como le senala Cohen a Ortega: aeste Sancho emplea siempre la misma palabra de que hace Fichte el fundamento para su filosofias y que no es otra que hazana (Tathandlung) (II, 559).

5. Véase la caracterización de la moral socratica en los términos mencionados en Etica de los griegos:, especialmente en III, 542 .

6. Aludo, a la que ofrece en El crepúsculo de los tdolos, Madrid, Alianza, 1973, pp. 37-43. Parece que Ortega la tiene presente cuando en la mencionada *Ética de los griegos escribe: «S6crates, con su sonrisa nihilista, feroz, a lo Lenin, en medio del ágora, dejando knock-out a un estratega ilustre, a un politico famoso, a un agudo sofista. (III, 541).

7. Su reivindicación de la espontaneidad y de las virtudes animales hay que entenderla ironicamente, como una vuelta táctica orientada a - ocultar el telos de su preocupación: un nuevo modelo de razón. En ningứn caso pretende Ortega sustituir a la razón por espontaneidad, sino abrir aquella a lo que le da suelo y de cuyo olvido se habría seguido la desviación idealista, a cuya crisis está asistiendo el siglo $\mathrm{Xx}$.

8. La estructura formal en la expresión del resentimiento - escribe Scheler- es aqui siempre la misma: se afirma, se pondera, se alaba algo: $A$, no por su intima calidad, sino con la intencion -que no es verbalmente expresada- de negar, de desvalorar, de censurar otra cosa, B*, El resenttimiento ent moral, Buenos Aires, Espasa Calpe, $1944^{2}$, p. 57 .

En cualquier caso, el lugar clásico para caracterizar el resentimiento es Nietzsche: el resentimiento es incapaz de ala auténtica reacción, la reacción de la acción [...] Mientras que toda moral noble nace de un triunfante si dicho a si mismo, la moral de los esclavos dice no, ya de antemano, a un "fuera", a un "otro" a un "no-yo"; y dse no es lo que constituye su acción creadorax, La gencalogia de la monal, Madrid, Alianza, 1972, pp. $42-43$.

9. «La magnanimidad como expresión de la autenticidad para don Jose Ortega y Gasset*, Didlogos (Puerto Rico), n." 37 (1981), pp. 83-94, cit. p. 92.

10. Es sabido que Ortega no ha dejado ningún tratado o reflexión sistemático sobre ética. Acaso no lo necesite un pensamiento que es en su raiz más profunda reflexión sobre el quehacer humano, sobre su justificacion y salvaciones. Pero convendra matizar, dadas las características de las presentes notas, en qué sentido hablaba Ortega sobre lo ético. En un trabajo de 1926, distingue entre la moral como un conjunto de normas ideales y la ética, que representaria su justificación ideologica. Ninguna de las dos le intereso demasiado. All mismo define el término ethos como eel sistema de reacciones morales que actuan en la espontaneidad de cada individuo, clase, pueblo, épocas. Asi, el ethos avendría a ser como la moral auténtica, efectiva y espontánea que de hecho informa cada vida* (II, 506-507). Quien este familiarizado con el pensamiento orteguiano vera que es de ethos de lo que habla Ortega cuando habla de seticas. Creo que, por ejemplo, la teoria del héroe de Meditaciones podria describirse como la propuesta de un ethos para la circunstancia española de su tiempo.

11. O para ser exactos: el imperativo pindárico remite a la metafora aristotelica del arquero, pues la primera alusión a la sustancia ética del mandato es de 1916: No midamos, pues, a cada cual sino consigo mismo: lo que es como realidad con lo que es como proyecto. "Llega a ser el que eres." He ahi el justo imperativo (II, 38). Y la referencia al arquero es de 1921.

12. Empleo el término entrecomillado porque quiero que retenga algo del viejo sentido religioso: renacimiento a otra forma de vida provocado por una revelación. Quien acepte el imperativo pindárico, reconoce la existencia de un *mandatox que es necesario satisfacer, aunque como tal no sea formulado expresamente $y$, desde luego, no venga de ninguna instancia exterior a la del propio yo. Esta compleja cuestión es desarrollada por Ortega bajo el concepto de «vocación». En su trabajo La voluntad de aventura el profesor Cere- 
zo ha serialado ya la alusión religiosa que encierra el término vocación* en Ortega.

13. La voluntad de aventura, Barcelona, Ariel, 1984, p. 126.

La siguiente cita, precisa con toda claridad el nuevo matiz que introduce Ortega en su visión del ideal, concebido como una dimension ajena, extranjera pero influyente respecto de lo real; aEs condición de todo ideal no ser posible realizario. Su papel consiste más bien en erguirse más allá de la realidad, influyendo simbólicamente sobre esta, a la manera que la estrella influye sobre la nave* (II, 434). Al defender su ajenidad, se distancia del utopismo $y$ al sostener su capacidad orientadora evita la resignacion y el culto a lo mostrenco, inevitables sin ilusión de ideales.

14. El sistema de Ortega y Gasset, Madrid, Alca1A, 1968, p. 401 .

15. La etica de Ortega, Madrid, Taurus, $1966^{3}$. Para lo que sigue, cf. capttulo III, NNi una ética vitalista, ni una ética existencialy, pp. 31-36.

16. Vease p. 34, n. 25 , en donde Aranguren remite a la obra de Ferrater: Ortega y Gasset, etapas de una filosofía.

17. Aranguren, op. cit., p. 32.

18. Ibid., p. 31 .

19. Inmejorable la descripción que de este ideal deportivo que venimos comentando hace Domingo Blanco en E. El aristocratismo de Ortegav (Sistema [Madrid], n." 76 [enero 1987]): - Para el hombre superior la vida es entrenamiento, palabra que traduce lo que en griego se decla ascetismo. La askesis era el régimen de vida que segufa el atleta, lleno de ejercicios y privaciones constantes, para mantenerse en forma. Toda vida noble acumula sobre sí misma dificultades y obligaciones, y eso es lo que la contrapone a la vida vulgar o inerte, que no exige nada especial, sino ser en cada instante lo que ya era, condenada a perpetua inmanencia mientras alguna fuerza exterior no la obligue a salir de sís (p. 84).

20. En ningún caso confunde Ortega este motivo suyo de lo deportivo -en donde tiene el sentido que tuvo en Grecia (cf. XII, 218-219) - con la creciente moda y afición a los deportes -espectaculo que empieza a desarrollarse en Europa hacia los años veinte y que fueron inmediatamente caracterizadas por el propio Ortega como sintomas de infantilismo.

Huizinga en su Homo ludens describe la esencia de lo lúdico en los siguientes términos: aEl juego es una acción u ocupación libre, que se desarrolla dentro de unos Ifmites temporales y espaciales determinados, según reglas absolutamente obligatorias, aunque libremente aceptadas, acción que tiene su fin en sl misma y va acompañada de un sentimiento de tensión y de la concien- cia de "ser de otro modo" que en la vida corriente», Madrid, Alianza-Emecé, 1972, pp. 43-44. El esfuerzo deportivo de que habla Ortega se basa, precisamente, en asumir la propia vida como una tensión hacia metas no elegidas, con reglas impuestas pero aceptadas, en la pretensión de que la vida tenga otra faz que la cotidiana: vida plena o felicitaria.

En definitiva, creo que se alcanza plena claridad sobre esta idea de lo deportivo si recordamos que Ontega la contrapone a la santificación del trabajo que habra practicado el siglo xix: en efecto, el trabajo es kesfuerzo obligado, impuesto por determinadas finalidades. *Al trabajo se contrapone otro tipo de esfuerzo que no nace de una imposicion, sino que es impulso liberrimo y generoso de la potencia vital: el deporte. [...] A las obras verdaderamente valiosas sólo se llega por mediación de este antieconomico esfuerzo: la creacion cientifica y artistica, el heroismo polftico y moral, la santidad religiosa son los sublimes resultados del deporte. (III, 195).

21. Vease la glosa que dedica Ortega al cuadro de El Greco El martivio de Sant Mauricio en *Muerte y resurreccion* (1917). Indudablemente, el gesto con que Mauricio invita a sus compañeros al martirio es un gesto edeportivo* en el sentido orteguiano: sopesado, sin gravedad y acaso un punto jovial.

22. Con esto no se está negando la obviedad de que las tesis orteguianas se compliquen, enriquezcan, digan más después que antes; aunque seguin el modelo propuesto por el propio Ortega para entender el progreso en filosofia, en donde avanzar es propiamente un sretroceders, una *ankbasis . hacia los stupuestos, la autenticidad que aparece desarrollada después, "está* antes de la ética deportiva.

23. Y en un sentido marcadamente igual al de la supuesta etapa vitalista. A título de ejemplo: * Y ese aceptar liberrimamente un penoso esfuerzo, es la definición misma de esfuerzo deportivo. (XII, 219) (1940). Véase ademixs: $V, 351$ (1933); V, 428 y 469 (1942); VII, 469 (1946); IX, 753 (1946); VIII, 306-307 (1947).

24. C. «Estética en el tranvia , de ese mismo año (II, 38), citado en la nota 11 y Espana invertebrada (1921) (III, 102), entre otros.

25. El motivo de la crisis historica es recurrente a lo largo de toda la obra de Ortega. De ahí que Huescar haya propuesto en su ensayo "Una cala en la perspectiva filosofica de Ortega* caracterizar ésta como wuna filosoffa de y para la crisis», Revista de Filosoffa (Instituto luis Vives» del CSIC, Madrid), n." VII (enero-junio, 1984), p. 26. 